\section{Analysis of www.AntarcticGlaciers.org as a tool for online science communication}

Academic research into climate change is driven by humanity's pressing concerns about environmental, health, technological and societal issues (Harris, 2011). Scientific outreach, the effective communication of this research, is increasingly important (Maddrell, 2010; Brewer and Ley, 2013) and is driven by mandates by research councils (Warren and others, 2007; Royal Society, 2008; NERC, 2011; Smith and others, 2013), a desire to broaden the impact of scientists' findings or to make research accessible to policy makers (Oppenheimer, 2011). Increasing numbers of researchers are participating in public engagement (Peters and others, 2008a,b; McComas and others, 2009). A key question is how can time-limited researchers, while working in full-time academic positions, implement effective outreach strategies with limited budgets?

Science communication can utilize press releases and media interviews (Corbett and Durfee, 2004; Boykoff, 2008; Allgeier and others, 2013), commissioned television programmes (Harris, 2011; Stewart and Nield, 2013), museum displays, public events such as science cafés, public lectures and debates, open days and exhibitions (Besley and Tanner, 2011; NERC, 2011) and online digital media. However, press releases and media interviews are usually available only to well-established scientists upon the publication of their work in significant journals, limiting greater dissemination of scientific findings and clear explanation of fundamental scientific concepts. More scientists do not appear regularly on television programmes due to time constraints, a lack of funding, training or opportunities, and a lack of support from colleagues and managers (Harris, 2011; Stewart and Nield, 2013). The effectiveness of science community events is limited by the numbers of people attending, the lack of time to explain key concepts, and the number of events it is practical for researchers to attend. However, public events have been criticized as fulfilling the deficit-knowledge model of communication, or 'preaching to the choir', with most visitors to science museums and public events already being well-educated, science-minded advocates (Nisbet and Scheufele, 2009).

Increasing internet use, however, offers new opportunities for science communication. For example, in the United States, the internet is pervasive, with $87 \%$ of American online adults using it to research scientific topics (Horrigan, 2006). Some $60 \%$ of American adults cite the internet as their primary source of information (National Science Board, 2012). Online digital media, including websites, weblogs (blogs), micro-blogging services such as Twitter, podcasts, infographics and other artwork, YouTube videos and other outlets, may all be utilized for science outreach (Ashlin and Ladle, 2006), although each is not without its own specific challenges (Table 1).

Because of this pervasive internet use, particularly in the developed world, a growing number of scientists are using digital media to engage directly with non-scientists, share information and opportunities, promote their research, build networks and forge new links and collaborations (Butler, 2005; Bonetta, 2009; Fox, 2012; Xin and others, 2012; Darling and others, 2013). Further, well-established and reputable online sources can play a role in expanding access to scientific information, particularly as wireless broadband expands to new regions and populations.

The benefits of digital media are that it can deliver almost instant science commentary (Bonetta, 2007) and fill gaps in traditional science journalism (Wilkins, 2008; Bubela and others, 2009), providing rich context and content, while drawing parallels with and referencing and linking to other

Table 1. Common challenges and mitigations for scientists engaging in online science communication (Peters and others, 2008a; Besley and Tanner, 2011; Harris, 2011; Somerville and Hassol, 2011; Bik and Goldstein, 2013; Darling and others, 2013; Smith and others, 2013; Stewart and Nield, 2013)

Challenges

Mitigations

Limited career credit given for publicizing work

Fear of misrepresentation by journalists; journalistic reports are too simple or brief

Insufficient time to develop a blog or website or wider outreach efforts

Fear of attack from sceptics or denialists

Criticism from peers for not spending enough time on teaching or research; poor career credit Fear of being unsuccessful or ignored

Fear of breaking institutional rules or norms

Fear of posting incorrect content, which is not peer-reviewed

Not making a difference or not being able to reach the general public

Not being very good at wider communication and engagement
Communication of research results increases the impact of publications. Publicly funded science should be widely available to the general public. Academic institutions and tenure committees should reward time and effort devoted to outreach.

Scientists should endeavour to work with journalists, developing good communication skills and an understanding of journalistic process.

Range of options available, from guest blogging, to tweeting, curation of existing media or editing Wikipedia. Join community outreach efforts.

As a scientist, it is vital to be able to defend your work and research. This is an important skill for young researchers to develop. Refer to robust, peer-reviewed research wherever possible. Make considered statements and posts.

Outreach and blogging is increasingly seen as a useful skill and a vital part of publicly funded research, but it should not take the place of academic scholarship. Joining a thriving online community is an excellent way to build attention and support. Check institutional regulations and work with press and communications officers and funding agencies beforehand.

Be willing to correct a mistake if it is pointed out - just as you would in other work. Encourage commenting and discussion on posts.

Thoroughly research intended audience and start with a well-thought-out outreach strategy.

Writing and communication skills only develop through practice. Read up on the wider literature on communication skills, and request university or departmental courses in science communication skills. 
recent findings (Wilkins, 2008). Among the most popular digital media are websites, blogs and micro-blogging services such as Twitter. We note that they each have different purposes and functions: Websites (where information is arranged topically) may be better as an educational resource, whereas blogs (where information is arranged chronologically) are often more reactive, with posts about new research and publications (Goldstein, 2009). Websites can encourage dialogue through comments, contact forms, discussion forums and embedded blogs. Blogs are more likely to have two-way dialogue through commenting than websites, and tend to build a community of regular visitors. Twitter encourages the most direct and immediate form of engagement.

There are a number of criticisms of the use of digital media as a tool for science communication, including that it generally only reaches a few already knowledgeable science enthusiasts and professionals (Bubela and others, 2009; Kouper, 2010). Indeed, internet use correlates with income, gender, education and location: people using the internet for research are likely to be affluent and relatively well educated (e.g. Flores, 2003, from research in Chile). Critical evaluation of the effectiveness of digital media in science communication is rare (Shema and others, 2012). Blogs and websites may also reinforce the knowledge-deficit model of science communication (Bubela and others, 2009). Kouper (2010) found that blogs and websites rarely provide the extensive critique or articulation on controversial issues that they may claim. Finally, websites and blogs are timeexpensive, require skill and research and may provide academics with limited career credit (Table 1).

Here we evaluate www.AntarcticGlaciers.org, a website with an embedded blog and Twitter feed, established to communicate peer-reviewed science to the general public. We collect together relevant science communication literature and outline the rationale and objectives of the website, before evaluating the degree to which these goals have been achieved 18 months after the website's launch. We conclude with a discussion and recommendations for other practitioners of online research communication and outreach.

\section{RATIONALE AND OBJECTIVES}

We developed www.AntarcticGlaciers.org in July 2012 to communicate our science and research. The rationale was that glaciers, ice sheets and their dynamic response to environmental changes are frequently poorly understood by the population at large (Hambrey and others, 2010; Francek, 2013), and there is a lack of informative websites available to the interested public. The goal of AntarcticGlaciers.org was therefore to communicate key scientific concepts and to deliver new research findings and scientific articles to the public and to other academics. Our objectives were: (1) to clearly explain and illustrate key concepts in glaciology as well as the latest scientific developments in Antarctic research, from our own and others' research; (2) to provide information well aligned with undergraduate and school national curriculums, supporting university and school learning; and (3) to include interactive features and social networking tools to encourage user engagement and discourse.

The intended audience for AntarcticGlaciers.org is broad, including school students (16-18-year-olds), interested adults, university students and other academics. A focus group held with school geography students and their teacher indicated that the key components that students look for in an educational website include a clear layout, an explanation of the system with its key concepts richly illustrated with photographs, and good search functionality. In general, the website must be professional and well put together, and critically it must be easy to navigate. Students were particularly interested in the exploration of Antarctica, changing glaciers, climate change and wildlife. They were also interested in information on geoscience careers, work experience, links to organizations and study advice. They emphasized that making a website appear personal and 'human' was essential. The professional association for geography teachers in Britain, the Geography Association, also made a number of valuable suggestions and recommendations.

The website is structured to be as easy to use as possible. The homepage includes a top navigation bar, a slideshow, an image panel, and text designed to draw readers into the website (Fig. 1). Search functionality, Facebook 'Like' and Twitter buttons and a 'Most Popular' side bar are designed to increase usage, interaction and engagement. The website's thematically organized webpages are well grounded in the scientific literature and cite relevant papers. Pages are written by one main author, with occasional guest posts by other academics. Dynamic interactive content includes embedded YouTube videos, quizzes, Google Maps and 'Prezi' slideshows. Throughout, the authors are emphasized as people, with photographs and headshots. Each page is richly illustrated with our own or publicly available images (Fig. 1). The webpages are written in accessible language with the minimum of jargon. Summaries of each author's peer-reviewed papers, upon publication, are uploaded as webpages with a prominent link to the online journal's version and the citation. The blog includes news, information and commentary on new publications, field diaries, and comments on careers, science communication and other broader topics of interest.

The science themes are aligned with the UK schools National Curriculum, although the content of the website goes beyond this. A section of the website dedicated to 16-18-year-old UK school students identifies which pages should be read by those studying for exams; common misconceptions about glaciers; suggested practice essay questions; resources for teachers; and interactive projects that can be undertaken by students. For university students, there are pages on study advice, essay-writing tips and careers. There is also a links page and a glossary.

The website is fully integrated with social networking tools in order to promote direct engagement with the target audience. Website updates and new content are advertised and promoted on Twitter. Twitter is also used to share journal articles, post opinions, deliver updates on conferences and professional opportunities, as well as photographs and short facts about glaciers, aimed at the general public. Other interactive features of the website designed to encourage discourse include an 'Ask a Scientist' and 'Answers to your questions' feature, a feedback survey, and commenting ability on all pages and posts. The ability to collect feedback and respond to the specific needs of the audience allows the website to be more useful to the intended audience, and makes it a more effective vehicle for science communication. 


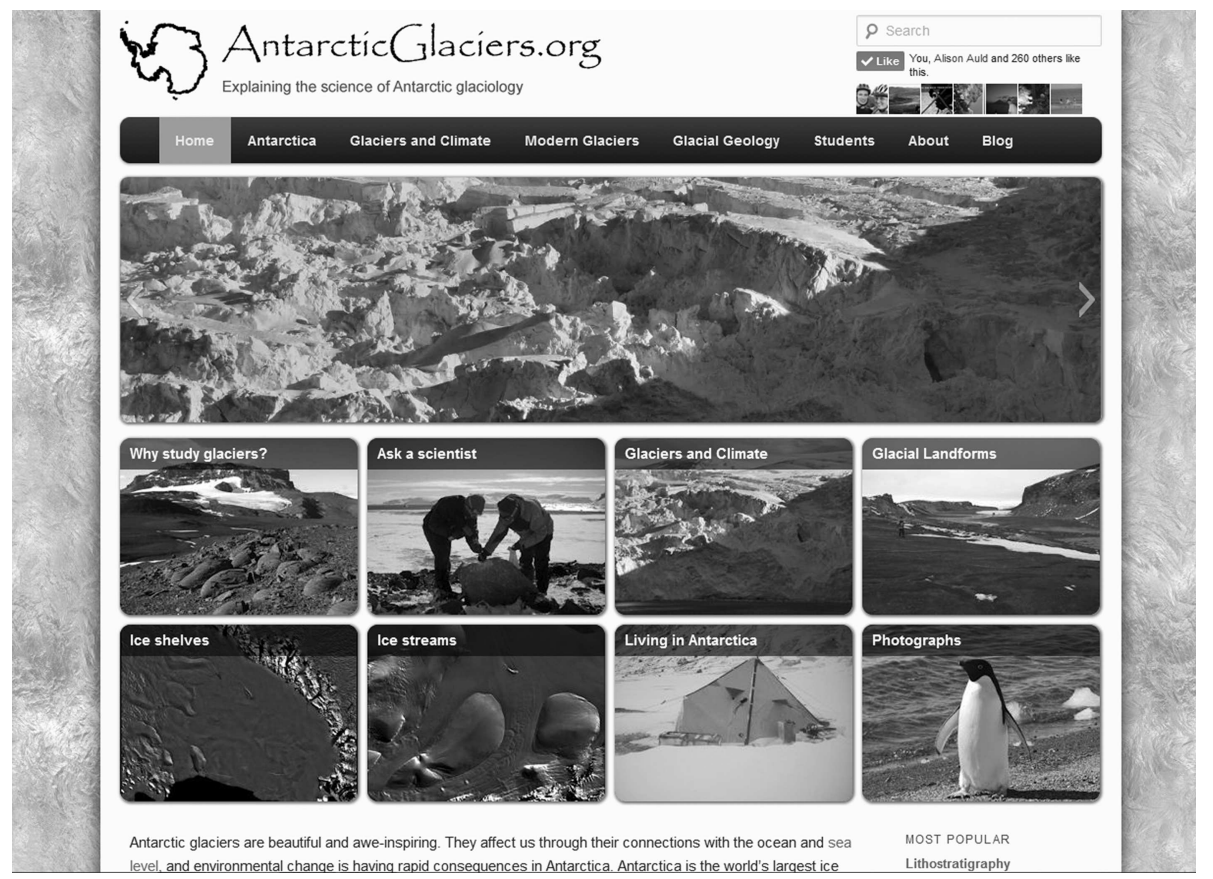

Fig. 1. Screenshot of AntarcticGlaciers.org homepage.

\section{EVALUATION}

Eighteen months after launch (1 July 2012 to 31 December 2013), AntarcticGlaciers.org had become highly visible on Google, and the number of Twitter followers had reached 1415. Over 1000 unique visitors landed on the website per week, and as of 31 December 2013 it had received $>73000$ visitors (>57 000 unique visitors) and $>150000$ page views (Fig. 2a). $22.3 \%$ of the hits are by returning visitors. There were visitors from every continent. The website is well targeted for certain search engine optimization (SEO) terms, resulting in increasing traffic from organic searches (Fig. 2b), while direct traffic contributes only a fairly static 1000 visitors per month. AntarcticGlaciers.org has received incoming links from several other websites, including high-profile university websites, and as a result the homepage has a Google PageRank of 4 . To date, $60 \%$ of visitors have found the website by searching through Google, $11.9 \%$ through a referral and $15.9 \%$ from direct traffic (Fig. 2c; cf. Table 2).

To ensure that the website was meeting the needs of its users, an anonymous feedback survey was initiated; there were 44 respondents. This survey was initiated throughout the site lifetime. There were equal numbers of male and female respondents, with the largest subset being in the 22-35-year-old age bracket (50\%; Table 3). The majority of survey respondents gave their occupation as 'At university' (Table 4). It has proven difficult to obtain feedback from school (UK Advanced-level (A-level)) students. We note that although A-level students may be looking at the website, they have little incentive to complete the survey, whereas teachers and researchers have more reason to support the website. The reasons given for looking at the website included general interest $(75.0 \%)$, to help with their studies $(28.1 \%)$ and because they were a researcher in a related field (31.3\%). Academics made up $26 \%$ of the website's visitors (Table 4), which supports our 'dissemination of scientific articles' goal.
When asked what they liked about the website, respondents primarily referenced the easy navigation and well-organized site structure, the site's informative nature, photographs and maps, the accessible language, the simple and thorough science themes, and the fact that it had an upbeat approach and was less 'serious' than other, similar sites (Fig. 2c). Respondents consistently cited the blog, fieldwork diaries and photographs as their favourite part of the website, with the specific 'Students' and 'Careers' sections coming in second. The most popular posts are the more general blog posts about careers and study strategies. This supports the findings of Bonetta (2007), who stated that the most popular blogs do not write only about science.

Suggestions for improvements received in the survey included more, and larger, photographs, especially in the glossary, more maps and diagrams, increasing links both within-site and to external sites, more content and science pages, and more 'human interest', such as the day-to-day life of a researcher, fieldwork diaries and interviews (Fig. 2d).

Analysis of the short biographies of the 1415 followers of the AntarcticGlaciers.org Twitter feed (@AntarcticGlacie) 18 months after launch (Fig. 2f) showed that although a large portion of Twitter followers self-identified as postgraduate geosciences students (153 people; $10.8 \%$ ) or academics with a professional interest in Antarctic glaciology (131 people; 9.3\%), the Twitter feed is also followed by a high number of non-scientists with no professional interest in glaciology (448 people; $31.7 \%$ ). It is also followed by 68 undergraduate students $(4.8 \%), 34$ teachers or school departments $(2.4 \%), 94$ journalists, science writers or communicators $(6.6 \%)$, and 100 outreach organizations or charities $(7.1 \%)$. Twitter is therefore useful for publicizing our website and research to schoolteachers, journalists and academics from other disciplines. This distribution of followers is not dissimilar to that recently found for marine scientists (Darling and others, 2013) and demonstrates that the Twitter feed is useful for reaching people beyond the academic sphere. 
a

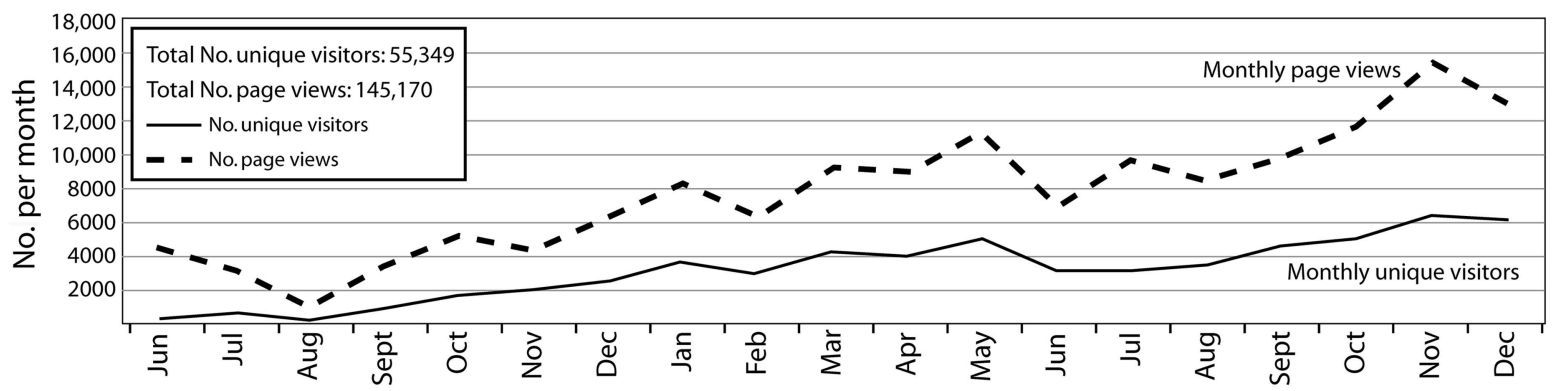

b

Month $(2012 / 13)$

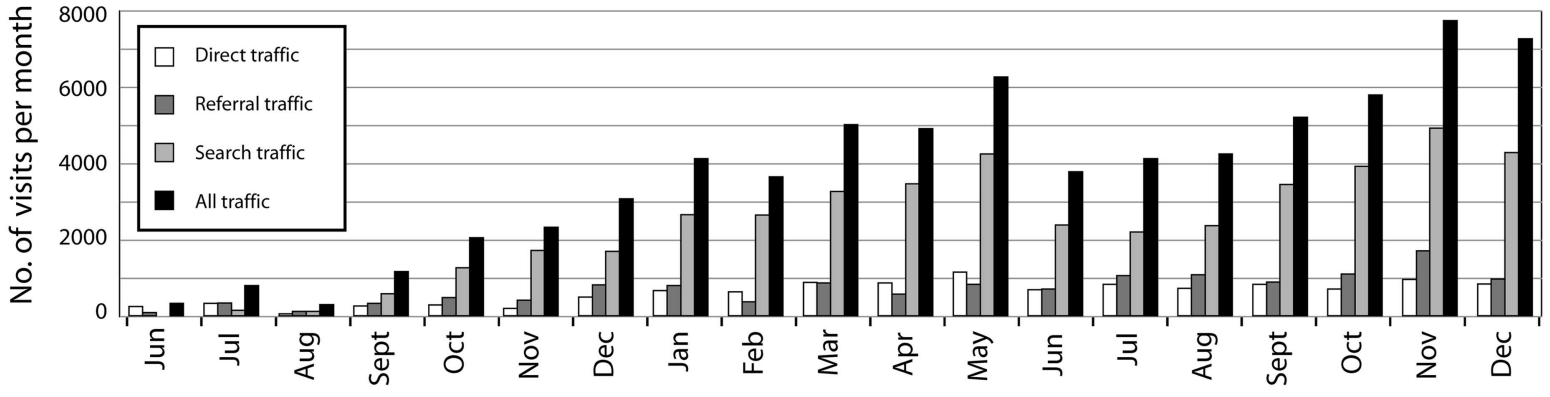

Months $(2012 / 13)$

C

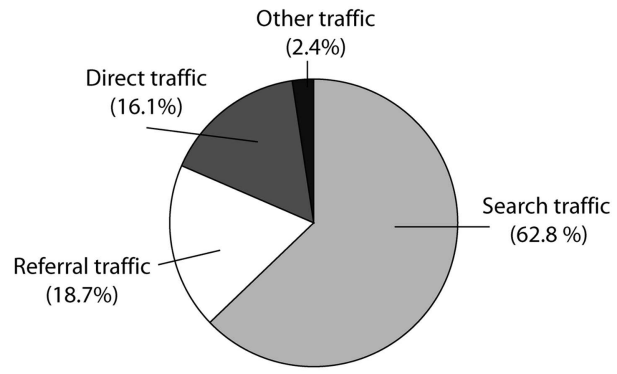

d
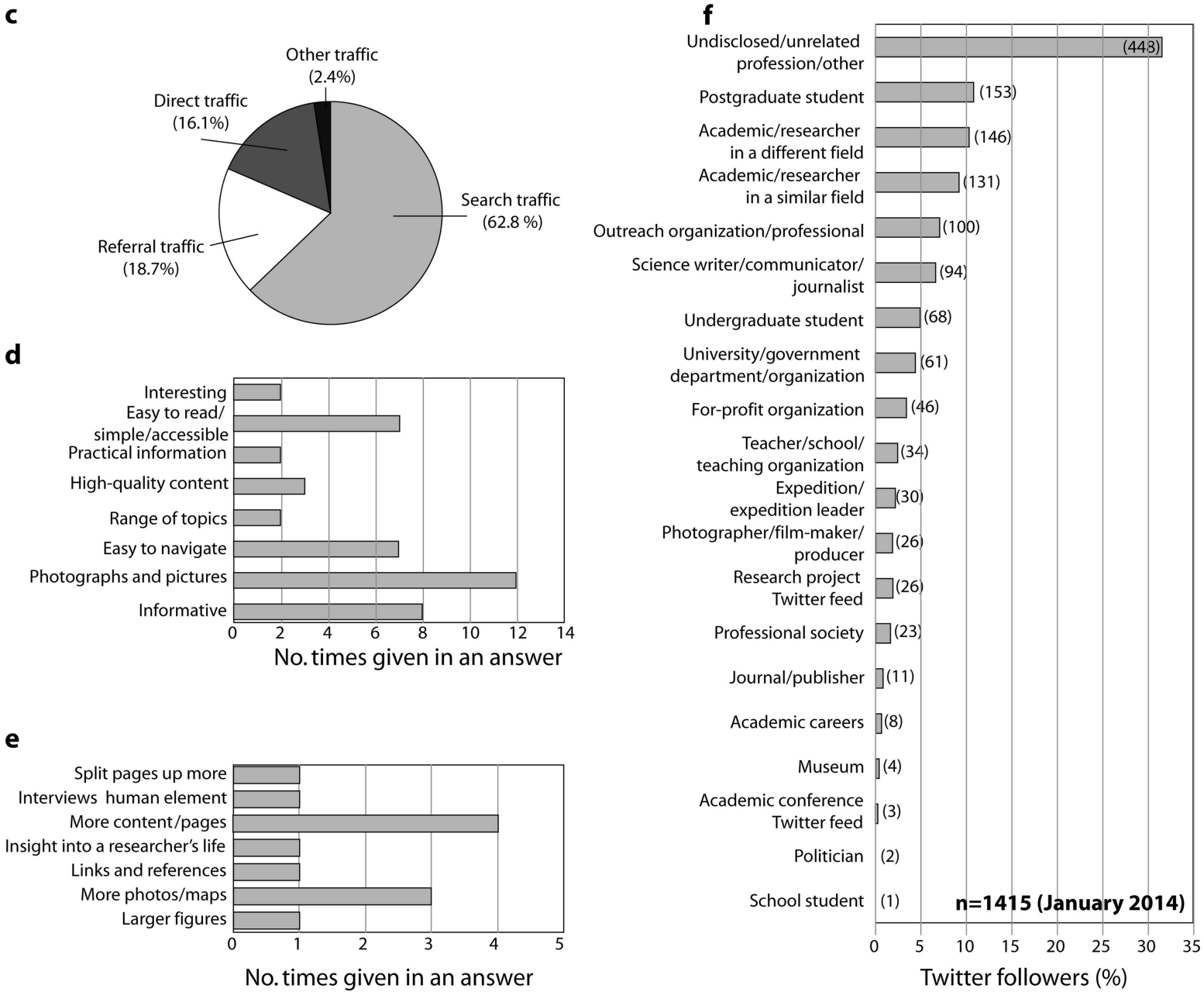

(\%)

Fig. 2. Analysis of visitors to AntarcticGlaciers.org (see Table 2 for definition of terms). (a) Unique visitors and page views, as determined over 18 months from website launch by Google Analytics. (b) Sources of traffic through time to the website (number of visitors per month). All traffic is unpaid (i.e. there was no paid advertising). (c) Sources of traffic to AntarcticGlaciers.org over the first 18 months. Search traffic includes people using Google, Yahoo or other search engines. Referral traffic includes people who have followed a link from another website. Direct traffic includes people who have typed in the URL directly. (d) Results of web-based survey, indicating the most common answers people gave in a free-text answer when asked what they liked about the website. (e) Results of web-based survey, indicating the most common answers people gave in a free-text answer when asked how the website could be improved. (f) Analysis of followers to @ AntarcticGlacie on Twitter, using self-identification given in the 'bios' on followers Twitter pages. Raw numbers are given in parentheses. 
Table 2. Definition of terms

\begin{tabular}{|c|c|}
\hline Term & Definition \\
\hline Website & A collection of thematically organized webpages served from a single web domain. \\
\hline Blog & A collection of chronologically organized 'posts', usually displayed in reverse chronological order. \\
\hline Social media & $\begin{array}{l}\text { The interactions between people online, where they create and share content in virtual communities and } \\
\text { networks. Twitter, a micro-blogging service, is one of the most popular social media platforms. }\end{array}$ \\
\hline PageRank & $\begin{array}{l}\text { An algorithm used by Google, named after Larry Page, which assigns value to a webpage based on a numerical } \\
\text { weighting of its incoming links. Webpages are given a PageRank of } 0-10 \text {, and the value indicates the } \\
\text { importance of a particular page. Pages with a higher PageRank are placed higher in Google search results. }\end{array}$ \\
\hline Author rank & $\begin{array}{l}\text { Author rank means that Google recognizes a particular person with a particular Google Plus profile as an author } \\
\text { of a particular webpage. The person's Google Plus profile picture appears next to the webpage in the Google } \\
\text { search results. People respond better to pages with a face next to them. Author rank is the mechanism by which } \\
\text { search engines, such as Google, prioritize pages based on how popular an author's other pages are. Being } \\
\text { recognized as a credible author will help prioritize your other articles. Claiming ownership of your online work } \\
\text { also helps Google establish the original author of a piece of text, meaning that it will prioritize your webpage } \\
\text { over another that has copied or plagiarized the content. }\end{array}$ \\
\hline
\end{tabular}

Search engine optimization (SEO) The process of increasing the visibility of a webpage in a search engine's unpaid, or 'organic', search results. SEO considers what search terms people type into search engines, and targets content to include these terms as 'keywords'. Keywords should appear in headings, URLs and the webpage text and figure captions. Users can also pay for Google Adwords to promote their site, which will result in 'paid traffic'.

Referral traffic The segment of traffic that arrives at a site through a link on another site.

Direct traffic

The segment of traffic that arrives at a site by typing the URL into a web browser.

Organic traffic

The segment of unpaid traffic that arrives at a site by searching in a search engine, such as Google, Bing or Yahoo.

Unique visitor

In Google Analytics, 'Unique visitors' refers to the number of distinct computers or users requesting pages from a website during a given period. If one computer requests the same webpage on three consecutive days, this would be one unique visitor with three visits. Unique visitors may be biased to overestimate the actual number of visitors if users delete cookies on their computer, or use different computers or browsers.

Page views

A page view is counted each time a webpage is rendered in a browser. Tracking page views in Google Analytics may be a more accurate measure of a website's popularity.

Overall, we found that AntarcticGlaciers.org has had some success at publicizing the research of the authors (observed through, for example, Twitter retweets, referrals, and anecdotal evidence), as well as broader concepts and ideas concerned with glaciers and climate. It is increasing in popularity and receives steadily more visitors (Fig. 2). For example, search traffic went from 140 visitors in July 2012 to a maximum (as of date of writing) of 4868 in November 2013. In May 2013, monthly unique visitors surpassed 4000 for the first time. The large proportion of organic search traffic received by the site ensures that it is easily accessible and easily found by members of the public, helping us to reach our target audience. These data show that the advantages of using social media, websites and blogs for science communication are many (Table 5). Online science

Table 3. Age of respondents of survey

\begin{tabular}{lc}
\hline Age bracket & Percentage of respondents \\
\hline Under 16 & $0 \%$ \\
$17-18$ & $0 \%$ \\
$19-22$ & $18.18 \%$ \\
$23-35$ & $50 \%$ \\
$36-65$ & $27.27 \%$ \\
Over 65 & $2.27 \%$ \\
Prefer not to say & $2.27 \%$
\end{tabular}

communication can reach a broad spectrum of society and bring research to the attention of journalists and science writers, who command larger audiences. AntarcticGlaciers.org provides a useful information resource that can supplement more direct public engagement, and our interactive website features and social media (e.g. Twitter) help to increase dialogue. We found that AntarcticGlaciers. org began to become effective within a relatively short time, but for optimum success, websites and blogs should be viewed as long-term, ongoing endeavours that will outlast specific research projects. Finally, our website and blog supports university and school pedagogy, by increasing the breadth and depth of knowledge of the lecturer, and by providing a supportive resource for schoolteachers and undergraduate and postgraduate students (Table 5).

Table 4. Occupation of respondents

\section{Occupation}

Percentage of respondents

At school or college

At university $0 \%$

In other full-time education

Scientist/researcher/academic

Teacher

Other full-time employment

Not working

Retired
$41.86 \%$

$22.33 \%$

$25.58 \%$

$6.98 \%$

$18.6 \%$

$4.65 \%$

$4.65 \%$ 
Table 5. Advantages and disadvantages of outreach websites and blogs as a means of science communication

\section{Advantages}

Disadvantages

Difficult to attract A-level students and younger adults to the website.

Analysis of Twitter followers and website users shows that, within just 1 year, a reliable section of the target audience (university students and the general public) has been reached. Using Twitter, 'Ask a Scientist' and blog post commenting allows engagement and dialogue.

Provides a useful information resource that can supplement additional and more direct outreach endeavours.

Website is a useful teaching resource, particularly for undergraduate and postgraduate students.

Website raises professional profile and 'brand'.

Website develops broader knowledge and understanding of scientific issues.

Website develops communication and writing skills.
Direct public engagement is limited in depth and detail. Some aspects of blogging and science communication websites do reinforce the knowledge-deficit model (Kellstedt and others, 2008; Bubela and others, 2009; Kouper, 2010). Blogging and websites need to be done in concert with other science communication means in order to be most effective.

Time-intensive; blogging requires a strong and ongoing time commitment (Bik and Goldstein, 2013).

Many of the website's visitors and Twitter followers have a professional interest in the themes on the website.

Websites and blogs often lack quality control, editing and rewriting (Wilkins, 2008).
Our evaluation shows that only 18 months after launch, the website is a useful resource, with some aspects that do challenge the deficit-knowledge model, with interactive features and a good understanding of the audience. It is a good supplementary tool to any outreach endeavour that seeks active dialogue with an audience. It reaches a broad spectrum of the population, including other academics, journalists, teachers, university students and the broader public. However, direct public dialogue is limited in depth and detail, so the outreach endeavour must be supported by other, more direct public engagement. In general, we find that creating a research outreach website or blog without careful consideration and thought can result in a largely ineffective tool. Without careful audience targeting and engagement, online tools for science communication may reinforce simple knowledge-deficit models (Table 5) and are at risk of being read by only a small number of science enthusiasts (Kouper, 2010). Researchers must invest time in $\mathrm{SEO}$ in order to be visible on Google. Finally, excellence in online science communication is a strong time-sink that requires ongoing commitment (Bik and Goldstein, 2013).

Together with the existing literature, our feedback survey and our website analysis, we can provide recommendations for excellence in outreach websites and blogs. Among the advantages of websites and blogs are that they can be quickly and cheaply set up using a number of pre-built platforms (e.g. Wordpress), which provide a professional layout and a simple content-management scheme. Careful SEO and targeting of the site's content to a specific audience helps academic blogs and websites avoid being lost in the blogosphere and can increase the number of hits. Installing a tool such as Google Analytics will allow tracking and analysis of the website and aid website evaluation. Identification of a website author, linked to a Google Plus profile, places your name and a headshot beside the page in the search results. People are more likely to click on pages with a headshot photograph. Google Authorship may, in the future, result in improved 'author rank' for highly rated authors, which may improve placement on Google search pages (Table 2).

A thematically organized website aids navigation and helps readers find the information they want. Using blogs on their own may be problematic for education and science communication, as it is difficult for users to explicitly find subjects they are interested in (Goldstein, 2009). However, like other embedded blogs (cf. Wilkins, 2008; Nisbet and Scheufele, 2009; Somerville and Hassol, 2011; Stewart and Nield, 2013), the AntarcticGlaciers.org blog provides more 'human interest' and is more reactive, commenting on recent news or publications. Our feedback survey highlighted the need for personal stories, photographs, narrative and emphasis on academic life, and we therefore encourage the dissemination of fieldwork, lab diaries or other forms of narrative. Without infringing copyright, both websites and blogs should make effective use of high-quality images as 'hooks', drawing people into the website (Miller, 1986).

An effective digital media strategy must carefully identify the intended audience and analyse their needs, and, crucially, their scientific understanding (Smith and others, 2013). Ideally, practitioners should meet their intended audience, perhaps by holding focus groups, engaging with school curricula or interacting with professional groups or societies. Our focus group meetings emphasized the need for careers and study advice, for clear pointers on relevance to the UK National Curriculum, and for an easy-to-navigate website structure. Reviews of the audience, through feedback surveys, Twitter and Google Analytics, can aid audience understanding and targeting. Our ability to respond to audience feedback has been crucial in providing a website that meets the needs of its readers.

Finally, websites and blogs can be a community effort, but authors need to have ownership, otherwise the attempt will fail. Institutions can support their staff and students' blogging efforts, for example, by providing free hosting, access to communications or website development training (Warren and others, 2007; Harris, 2011; Stewart and Nield, 2013), promotion of and links to blogs on university websites (Batts and others, 2008), career incentives to undertake excellence in outreach (Royal Society, 2008), funding (including of public events), and by providing press office support and online promotion. Academics can supplement training courses in science blogging by reading examples of best practice in public engagement by other scientists, journalists and bloggers.

Online science communication has numerous benefits for the researcher. For example, writing about new articles or topics requires a deeper understanding of the literature, which may often be outside the researcher's normal realm 
(Bonetta, 2007). Literature must also be read while it is fresh and new; the article needs to be written in a timely manner to be relevant. Writing articles in an easy-to-read, accessible format will help develop writing skills. Website authors and bloggers will gain a deeper understanding of the internet, programming and search engine optimization, all of which have practical uses in an academic career, and may even open up different career options. Bloggers are more aware of online resources, which may help develop innovative teaching resources. Figures, maps and conceptual diagrams are easily translated into lecture slides, and vice versa; indeed, blogging and teaching are mutually beneficial since science communication and pedagogy share many of the same skills, both being based in effective communication.

Using digital media professionally can increase the visibility and online presence of an early-career researcher, opening them to new collaborations and networks, and making them more visible to future employers. Blogging and tweeting about journal publications can increase their prominence and citations (Bik and Goldstein, 2013; Darling and others, 2013). Writing short summaries of published journal articles means that they are close to open access, with lay readers able to access the key findings of the work in simple, understandable language. Some writers use blogs to develop ideas and foster collaboration prior to submitting work to peer review (Fox, 2012).

\section{CONCLUSION}

We conclude that AntarcticGlaciers.org has been successful in communicating science to the wider public, although a high proportion of visitors and Twitter followers are scientists with a professional interest in Antarctic glaciology. We have had limited success in reaching school students. Some aspects do reinforce the top-down knowledge-deficit model, and this is limited by trying to encourage interaction and careful targeting of specific audiences. The feedback survey and focus groups allowed the website's content to evolve in response to the needs of its users. The ability to respond to the audience is a crucial step in challenging the knowledgedeficit model. The success of AntarcticGlaciers.org as an outreach tool was enhanced by using a combination of webpages and blog posts, with blog posts being more related to current news, recent publications or other more general topics. Twitter is important for promoting dialogue and relationships, for publicizing new posts and for reaching out to journalists, schoolteachers, other academics and the broader public. Search engine optimization is essential to build traffic. Using personal narrative and photographs was crucial to generate interest and engage readers of the AntarcticGlaciers.org website. We recommend the use of websites and blogs to other academics wishing to engage in public communication of science as a low-budget but timeintensive strategy.

In summary, a successful online outreach strategy must fulfil the following criteria: (1) identify and clearly understand the intended audience and their needs, and have the ability to evolve in response to the audience; (2) good search engine optimization is essential to build an audience; (3) the text should be easy to understand and illustrated with a strong narrative, human interest and plenty of photographs, with a small number of key details that are relevant to the audience; (4) the online strategy should encourage and allow engagement, conversations and direct interaction.

\section{ACKNOWLEDGEMENTS}

AntarcticGlaciers.org was supported and funded by the Quaternary Research Association (QRA) and the Scientific Committee for Antarctic Research (SCAR). It was developed and is maintained by www.Senktec.com, a website development company, who provide ongoing support. While the QRA supports this initiative, the views expressed are those of the authors and do not necessarily represent those of the QRA. This analysis was conducted while B.J.D. was a recipient of a SCAR Fellowship award and was visiting the Antarctic Research Centre, Victoria University of Wellington, New Zealand. B.J.D. was also funded by a UK Natural Environment Research Council grant through the Antarctic Funding Initiative (grant AFI 9-01; NE/F012942/1) awarded to N.F.G. We thank Rhian Salmon and Heidi Roop for constructive comments. We also thank two anonymous reviewers for thoughtful and constructive comments.

Centre for Glaciology,

Department for

Bethan J. DAVIES

Geography and Earth Sciences,

Aberystwyth University,

Aberystwyth, UK

E-mail: bdd@aber.ac.uk

\section{February 2014}

\section{REFERENCES}

Allgaier J, Dunwoody S, Brossard D, Lo Y-Y and Peters HP (2013) Journalism and social media as means of observing the contexts of science. BioScience, 63(4), 284-287 (doi: 10.1525/ bio.2013.63.4.8)

Ashlin A and Ladle RJ (2006) Environmental science adrift in the Blogosphere. Science, 312(5771), 201 (doi: 10.1126/ science.1124197)

Batts SA, Anthis NJ and Smith TC (2008) Advancing science through conversations: bridging the gap between blogs and the Academy. PLOS Biol., 6(9), e60240 (doi: 10.1371/journal.pbio. 0060240)

Besley JC and Tanner AH (2011) What science communication scholars think about training scientists to communicate. Sci. Commun., 33(2), 239-263 (doi: 10.1177/1075547010386972)

Bik HM and Goldstein MC (2013) An introduction to social media for scientists. PLoS Biol., 11(4), e1001535 (doi: 10.1371/ journal.pbio.1001535)

Bonetta L (2007) Scientists enter the Blogosphere. Cell, 129(2), 443-445 (doi: 10.1016/j.cell.2007.04.032)

Bonetta L (2009) Should you be tweeting? Cell, 139(3), 452-453 (doi: 10.1016/j.cell.2009.10.017)

Boykoff MT (2008) Media and scientific communication: a case of climate change. (Special Publication 305) Geological Society, London

Brewer PR and Ley BL (2013) Whose science do you believe? Explaining trust in sources of scientific information about the environment. Sci. Commun., 35(1), 115-137 (doi: 10.1177/ 1075547012441691)

Bubela T and 23 others (2009) Science communication reconsidered. Nature Biotech., 27(6), 514-518 (doi: 10.1038/ nbt0609-514)

Butler D (2005) Science in the web age: joint efforts. Nature, 438(7068), 548-549 (doi: 10.1038/438548a)

Corbett JB and Durfee JL (2004) Testing public (un)certainty of science: media representations of global warming. Sci. Commun., 26(2), 129-151 (doi: 10.1177/1075547004270234) 
Darling E, Shiffman D, Côté I and Drew J (2013) The role of Twitter in the life cycle of a scientific publication. Ideas Ecol. Evol., 6(1), 32-43 (doi: 10.4033\%2Fiee.v6i1.4625)

Flores C (2003) Measuring the relationship between ICT use and income inequality in Chile. University of Texas Inequality Project, Working Paper 26 http://utip.gov.utexas.edu/papers/ utip_26.pdf

Fox J (2012) Can blogging change how ecologists share ideas? In economics, it already has. Ideas Ecol. Evol., 5(2), 74-77 (doi: 10.4033\%2Fiee.v5i2.4457)

Francek M (2013) A compilation and review of over 500 geoscience misconceptions. Int. J. Sci. Educ., 35(1), 31-64 (doi: 10.1080/ 09500693.2012.736644)

Goldstein AM (2009) Blogging evolution. Evol. Educ. Outreach, 2(3), 548-559 (doi: 10.1007/s12052-009-0149-9)

Hambrey M and 6 others (2010) Glaciers - no nonsense science. Geoscientist [Online], 20(6)

Harris F (2011) Getting geography into the media: understanding the dynamics of academic-media collaboration. Geogr. J., 177(2), 155-159 (doi: 10.1111/j.1475-4959.2010.00396.x)

Horrigan J (2006) The internet as a resource for news and information about science. Pew Research Internet Project. Pew Research Center, Washington, DC http://www.pewinternet.org/ files/old-media//Files/Reports/2006/PIP_Exploratorium_Science.pdf.pdf

Kellstedt PM, Zahran S and Vedlitz A (2008) Personal efficacy, the information environment, and attitudes toward global warming and climate change in the United States. Risk Anal., 28(1), 113-126 (doi: 10.1111/j.1539-6924.2008.01010.x)

Kouper I (2010) Science blogs and public engagement with science: practices, challenges, and opportunities. J. Sci. Commun., 9(1), 26/02/2010

Maddrell A (2010) Academic geography as terra incognita: lessons from the 'expedition debate' and another border to cross. Trans. Inst. Br. Geogr., 35(2), 149-153 (doi: 10.1111/ j.1475-5661.2009.00372.x)

McComas KA, Arvai J and Besley JC (2009) Linking public participation and decision making through risk communication. In Heath RL and $\mathrm{O}^{\prime}$ Hair HD eds. Handbook of risk and crisis communication. Routledge, New York, 364-385

Miller JD (1986) Reaching the attentive and interested public for science. In Friedman SM, Dunwoody S and Rogers CL eds.
Scientists and journalists: reporting science and news. Free Press, New York, 55-69

National Science Board (2012) Science and Engineering Indicators 2012. National Science Foundation, Arlington, VA http:// www.nsf.gov/statistics/seind12

Natural Environment Research Council (2011) Engaging the public with your research. Natural Environment Research Council, Swindon http://www.nerc.ac.uk/publications/guidance/documents/engaging-the-public.pdf

Nisbet MC and Scheufele DA (2009) What's next for science communication? Promising directions and lingering distractions. Am. J. Bot., 96(10), 1767-1778 (doi: 10.3732/ajb.0900041)

Oppenheimer M (2011) What roles can scientists play in public discourse? Eos, 92(16), 133-134 (doi: 10.1029/2011EO160001)

Peters HP and 6 others (2008a) Interactions with the mass media. Science, 321(5886), 204-205 (doi: 10.1126/science.1157780)

Peters HP and 6 others (2008b) Science-media interface: it's time to reconsider. Sci. Commun., 30(2), 266-276 (doi: 10.1177/ 1075547008324809)

Royal Society (2008) Factors affecting science communication by scientists and engineers. The Royal Society, London

Shema H, Bar-llan J and Thelwall M (2012) Research blogs and the discussion of scholarly information. PLoS ONE, 7(5), e35869 (doi: 10.1371/journal.pone.0035869)

Smith B and 7 others (2013) COMPASS: navigating the rules of scientific engagement. PLoS Biol., 11(4), e1001552 (doi: 10.1371/journal.pbio.1001552)

Somerville RCJ and Hassol SJ (2011) Communicating the science of climate change. Phys. Today, 64(10), 48-63 (doi: 10.1063/ PT.3.1296)

Stewart IS and Nield T (2013) Earth stories: context and narrative in the communication of popular geoscience. Proc. Geol. Assoc., 124(4), 699-712 (doi: 10.1016/j.pgeola.2012.08.008)

Warren DR, Weiss MS, Wolfe DW, Friedlander B and Lewenstein B (2007) Lessons from science communication training. Science, 316(5828), 1122 (doi: 10.1126/science.316.5828.1122b)

Wilkins JS (2008) The roles, reasons and restrictions of science blogs. Trends Ecol. Evol., 23(8), 411-413 (doi: 10.1016/ j.tree.2008.05.004)

Xin S, Pepe A and Bollen J (2012) How the scientific community reacts to newly submitted preprints: article downloads, Twitter mentions, and citations. PLOS ONE, 7(11), e47523 (doi: 10.1371/journal.pone.0047523) 